\title{
Photoelectrochmeical Cell Based on Natural Pigments and ZnO Nanoparticles
}

\author{
Getachew Yirga $^{1}$, Sisay Tadesse ${ }^{3}$, Teketel Yohannes ${ }^{2}$ \\ ${ }^{1}$ Department of Physics, Haramaya University, Dire Dawa, Ethiopia \\ ${ }^{2}$ Materials Science Program, Addis Ababa University, Addis Ababa, Ethiopia \\ ${ }^{3}$ Department of Chemistry, Hawassa University, Hawasa, Ethiopia
}

Email address:

gyirga10@gmail.com (G. Yirga), teketely@yahoo.com (T. Yohannes), sisayt@hu.edu.et (S. Tadesse)

\section{To cite this article:}

Getachew Yirga, Sisay Tadesse, Teketel Yohannes. Photoelectrochmeical Cell Based on Natural Pigments and ZnO Nanoparticles. Journal of Energy and Natural Resources. Vol. 5, No. 1, 2016, pp. 1-10. doi: 10.11648/j.jenr.20160501.11

\begin{abstract}
Natural pigments extracts from Bougainvillea spectabilis, Carissa Ovata, Hibiscus sabdariffa, Amarathus iresine herbisti, Beta vulgaris, are used as natural sensitizers for a dye sensitized solar cell (DSSC). ZnO nanoparticles were synthesized using sol-gel method and the size of the nanoparticle was determined using effective mass approximation model. Devices were Assembled using $\mathrm{ZnO}$ nanoparticles and natural sensitizers. DSSCs based on ZnO nanoparticles and ethanol extract of Amarathus iresine sensitizers have shown relatively better conversion efficiency of 0.039 . Incident photon to current conversion efficiency (IPCE), short circuit current density (J $s c$ ) and open circuit voltage (Voc) were measured for all the sensitizers.
\end{abstract}

Keywords: Natural Dyes, Electrolytes, Solar Cells, Titanium Dioxide $\left(\mathrm{TiO}_{2}\right)$

\section{Introduction}

The development of dye sensitized solar cells (DSSCs), which have derived inspiration from photosynthesis, has opened up exciting new possibilities and prototypes for producing solar photovoltaics possibly at lower cost. Early DSSC designs involved transition metal coordinated compounds (e.g., ruthenium polypyridyl complexes) as sensitizers because of their strong visible absorption, long excitation lifetime, and efficient metal-to-ligand charge transfer. Because of these, such type of DSSC's are highly effective with maximum efficiency of $11 \%[1,2]$. The costly synthesis and undesired environmental impact of those prototypes call for cheaper, simpler, and safer dyes as alternatives. Natural pigments, including chlorophyll, carotene, and anthocyanin, are freely available in plant leaves, flowers, and fruits and fulfill these requirements. Experimentally, natural dye sensitized $\mathrm{TiO}_{2}$ solar cells have reached an efficiency of $7.1 \%$ and high stability [3]. Higher efficiency over $8.0 \%$ has been obtained using similar synthetic organic dyes [2].

Natural dyes have become a viable alternative to expensive and rare organic sensitizers because of its low cost, easy attainability, abundance in supply of raw materials and no environment threat. Various components of a plant such as the flower petals, leaves and bark have been tested as sensitizers. The nature of these pigments together with other parameters has resulted in varying performance. In this study pigments Bougainvillea spectabilis, Carissa Ovata, Hibiscus sabdariffa, Amarathus iresine herbisti, and Beta vulgaris were extracted as sensitizers and as a semiconductor $\mathrm{ZnO}$ and $\mathrm{TiO}_{2}$ were used. All the photoelectrochemical performance was measured and characterized for all the above sensitizers and semiconductors.

The solar cell efficiency was determined by its currentvoltage $(\mathrm{J}-\mathrm{V})$ characteristics under standard illumination conditions. A standard solar spectrum of air mass 1.5 (AM 1.5) with an intensity of $1000 \mathrm{~W} / \mathrm{m}^{2}$ is used for characterization. The $\mathrm{V}_{\text {oc }}$ is the difference in potential between the two terminals in the cell under light illumination when the circuit is open. $J_{\mathrm{sc}}$ is the photocurrent per unit area $\left(\mathrm{mA} / \mathrm{cm}^{2}\right)$. The degree of the squared shape of the J-V curve is given by the fill factor (FF), which measures the ideality of the device and is defined as the ratio of the maximum power output per unit area to the product of $\mathrm{V}_{\mathrm{oc}}$ and $\mathrm{J}_{\mathrm{sc}}$.

$$
\mathrm{FF}=\frac{\mathrm{I} \text { max.power } V_{\text {max.power }}}{\mathrm{J}_{\mathrm{sc}} \mathrm{V}_{\mathrm{oc}}}
$$


The solar to electric power conversion efficiency $\eta$ is given by the ratio of the maximum extractable power to the incident solar power $\left(\mathrm{P}_{\text {in }}\right)$ given by Equation 2 .

$$
\eta=\frac{P_{\max }}{P_{\text {in }}}=\frac{J_{\max } \cdot V_{\max }}{P_{\text {in }}}=\frac{J_{s c} \cdot V_{o c} \cdot F F}{P_{\text {in }}}
$$

Where $\mathrm{P}_{\text {in }}$ is the incident power, Pout is the output power, FF is the fill factor, $\eta$ is the efficiency, $J_{s c}$ is the short circuit current density, and $\mathrm{V}_{\mathrm{oc}}$ is the short circuit voltage. IPCE is one of the fundamental measurements of the performance of the solar. It is also known as the external quantum efficiency and describes how efficiently the light of a specific wavelength is converted to current that is (electrons out) / (photons in). The IPCE can be calculated according to the following equation.

$$
\operatorname{IPCE}(\%)=\frac{1240 \cdot \mathrm{J}_{\mathrm{Sc}}}{\lambda \cdot \mathrm{P}_{\text {in }}} \cdot 100
$$

$\mathrm{J}_{\mathrm{sc}}$ is the short circuit current density, $\lambda$ is the wavelength of the incident light and $\mathrm{P}_{\text {in }}$ is the intensity of the incident light. The factors determining the IPCE can be expressed as:

$$
\operatorname{IPCE}(\lambda)=\eta_{\text {lh }}(\lambda) \cdot \eta_{\text {inj }}(\lambda) \cdot \eta_{\text {col }}(\lambda)
$$

Where $\eta_{\mathrm{lh}}(\lambda)$ the light harvesting efficiency of the sensitized oxide layer, $\eta_{\text {inj }}(\lambda)$ is the electron injection efficiency from the sensitizer into the oxide, and $\eta_{\text {col }}(\lambda)$ is the electron collection efficiency.

\section{Materials and Experimental Methodology}

\subsection{Synthesis of ZnO Nanoparticles}

Zinc acetate $(\mathrm{BDH})$, sodium hydroxide pellets (Scharlau), and polyethylene glycol (Applied Science) were used as received. All the materials were first cleaned and rinse with distilled water and dried. All the chemicals were weighed with analytical balance and mixed in cleaned round bottom flask. For the sol-gel method $2.7 \mathrm{~g}$ of zinc acetate dehydrate and 0.5 $\mathrm{g}$ of polyethylene glycol (PEG) were taken and dissolved in in $250 \mathrm{ml}$ of distilled water separately. $2 \mathrm{~g}$ of sodium hydroxide was dissolved in $500 \mathrm{ml}$ of distilled water with vigorous stirring. The sodium hydroxide solution was added to the zinc acetate solution drop wise and the mixture was refluxed for 8 hrs. at $120^{\circ} \mathrm{C}$ using the setup shown in Fig 1.

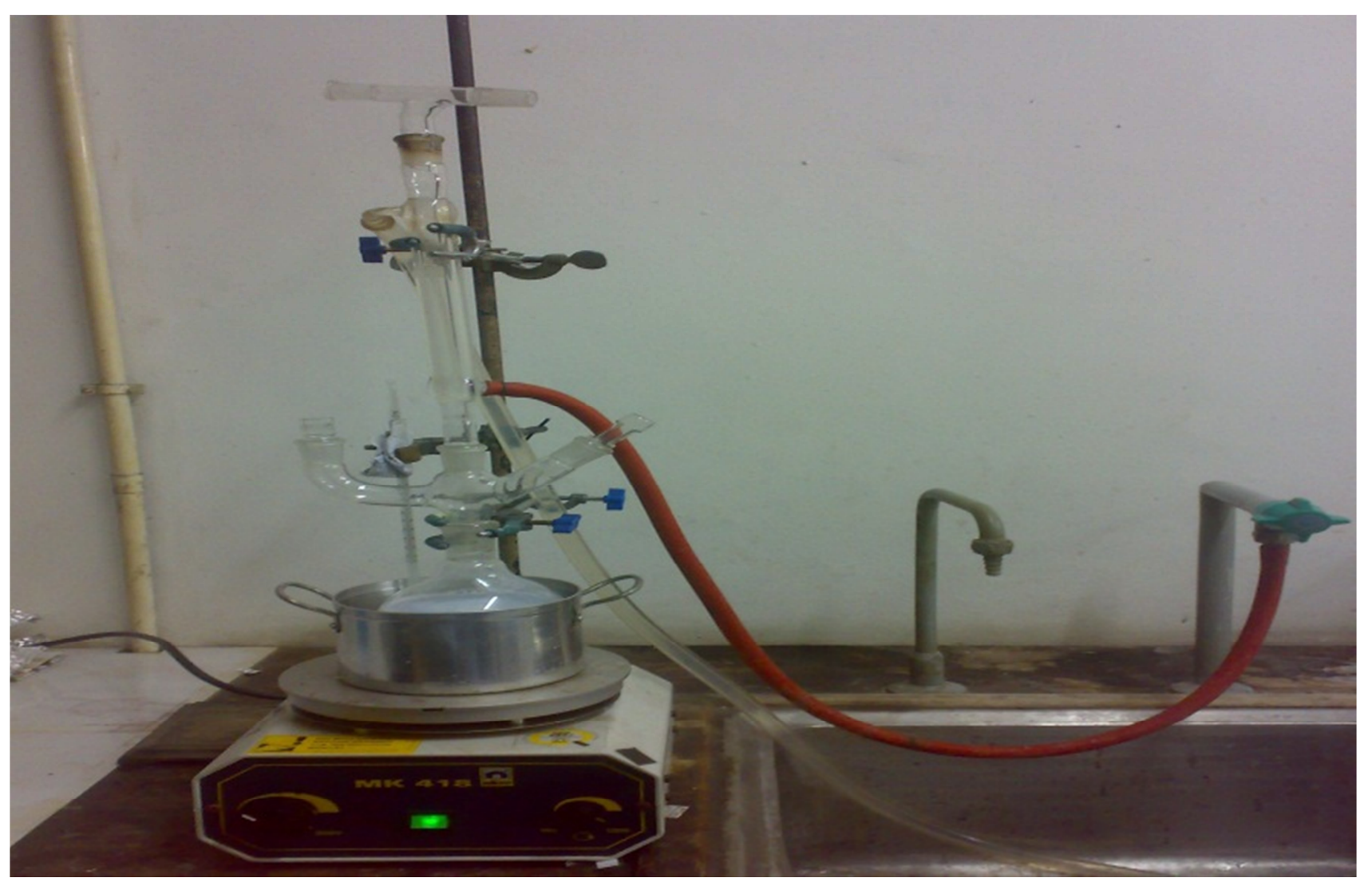

Fig. 1. Experimental set-up for refluxing the solution.

The obtained $\mathrm{ZnO}$ solution was centrifuged to solid matter and solution. The solid matter was washed first by distilled water repeatedly, finally dried in Furnace to obtain $\mathrm{ZnO}$. Diagrammatically the whole experiment can be summarized below. After preparing the colloidal nanoparticles optical absorption was done using Gensys-2 PC spectrometer to determine the size of colloidal nanoparticles. About $5 \mathrm{ml}$ of the colloid were taken for measurement. Here for measurement the colloid nanoparticles were taken as soon as they reach the final temperature. We record the UV-visible absorption spectra between 275 and $500 \mathrm{~nm}$. The solvent was used as a blank solution. 


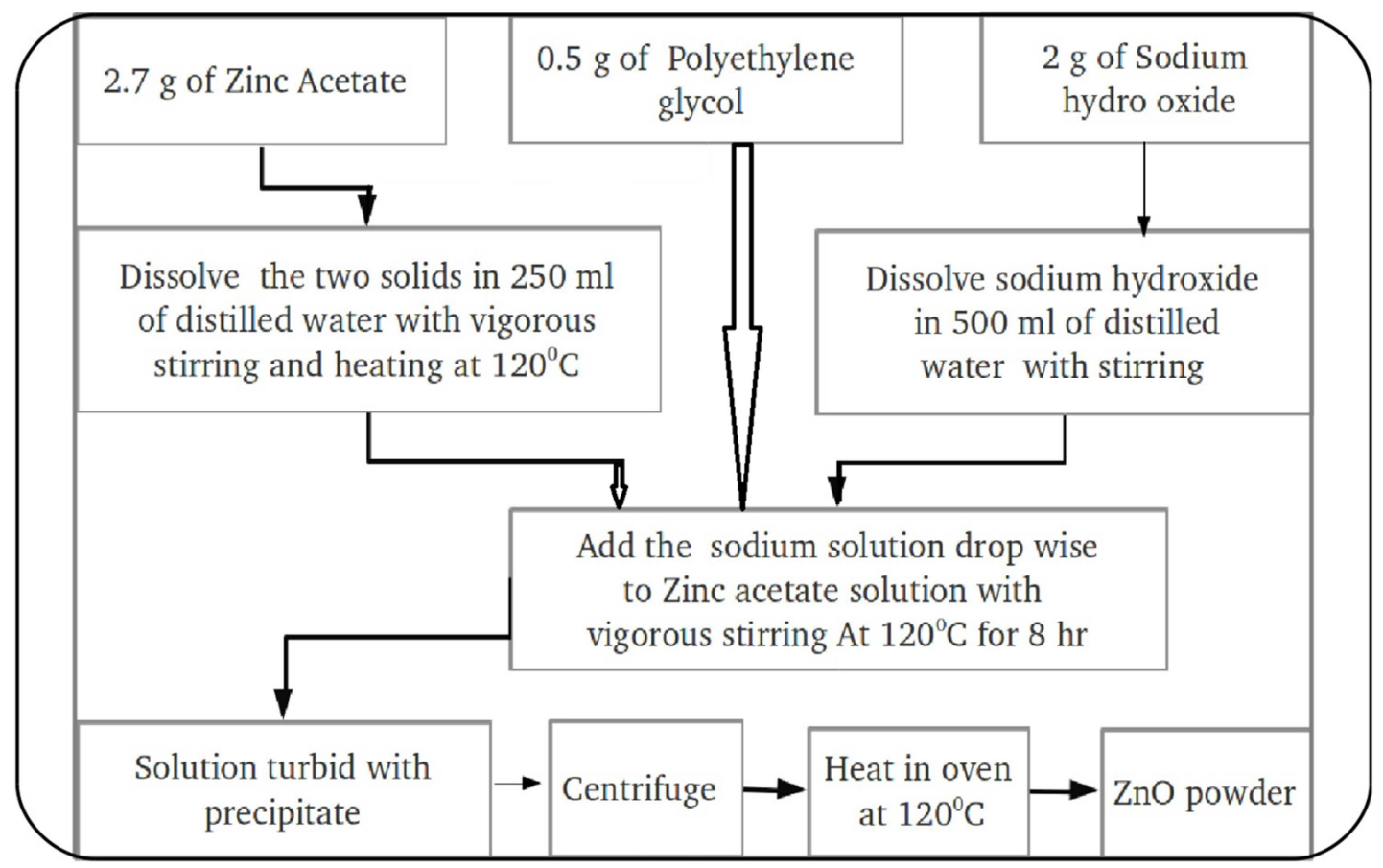

Fig. 2. Steps of $\mathrm{ZnO}$ synthesis.

\subsection{Natural Dyes Extraction}

To select the dye that has good absorption in the visible region, fresh fruits, leaves, and flowers of plants including, Beta vulgaris, Bougamvillea, Amarathus iresine herbisiti, Hibiscus sabdariffa, and Carissa ovata collected. The collected plant was dried at room temperature in a shade to prevent pigment degradation (see Fig.3). After drying for about 2 months the samples are completely dried in an oven at $70^{\circ} \mathrm{C}$ to avoid some moisture from it. Then after, the samples were crushed with Micro Plant Grinding machine to produce the powder of the respective plant materials. The dye extraction from the powder was done as follows; $2 \mathrm{~g}$ of each powder sample was taken and soaked in $50 \mathrm{ml}$ of ethanol for extracting using ethanol and in $50 \mathrm{ml}$ water for extracting with water in separate bottle.

The solution is stored at room temperature for about 6 hours to dissolve the powder completely. Then the solution was filtered with glass filter to separate the solid from the pure liquid. After filtration the extracted pigment in different solvent are shown in Fig. 4.

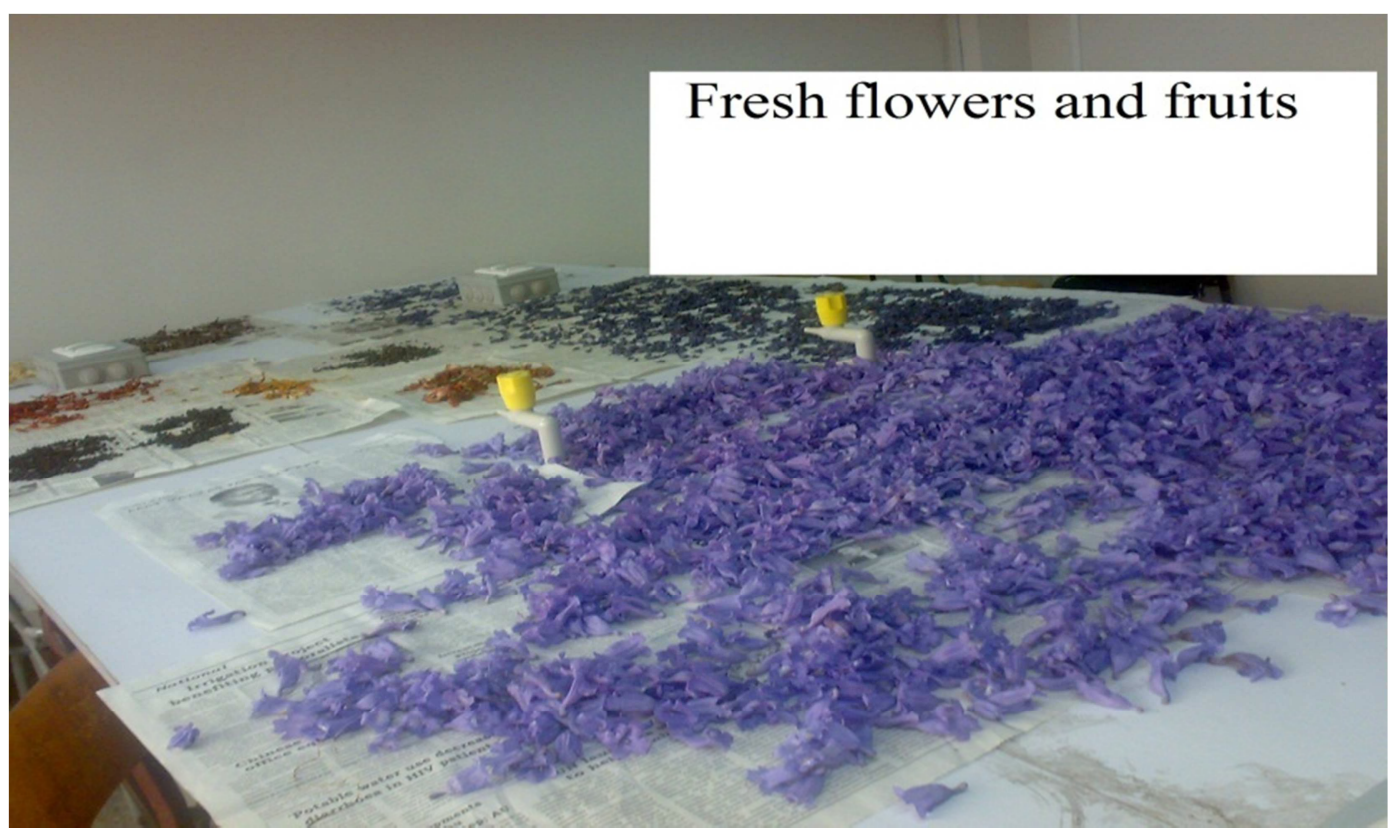

Fig. 3. Fresh flowers and fruits under room temperature. 


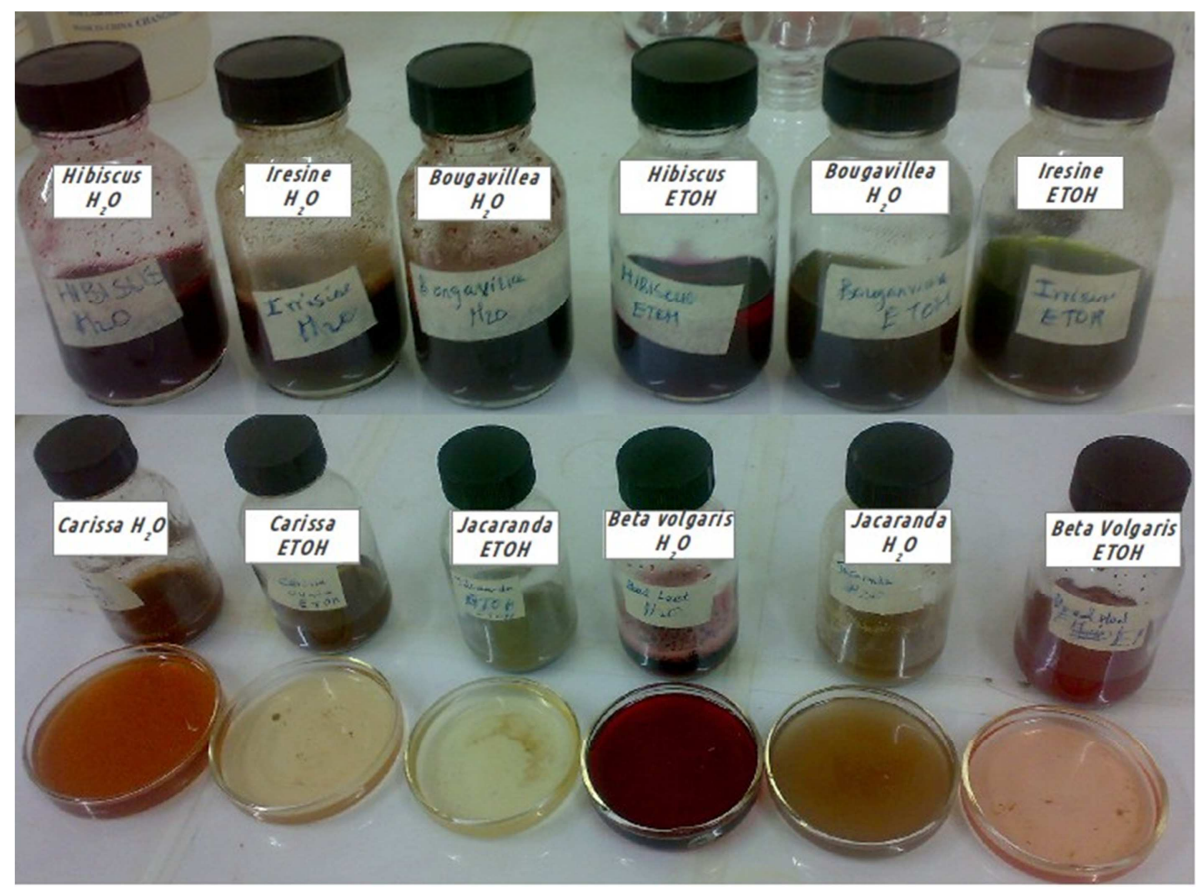

Fig. 4. Samples of extracted pigment.

The pigment shown in Fig.4 are ready for soaking the electrode inside it, and also used for measuring the UV-vis absorption spectra. The absorption measurement was carried using the Gensys-2 PC spectrometer for each extract.

\subsection{Fabrication of Dye-sensitized Solar Cells}

The materials and the fabrication method employed for the fabrication of dye-sensitized Photo electrochemical cells based on $\mathrm{ZnO}$ nanoparticles are described below.

\subsubsection{Substrate Cleaning}

The substrate cleaning is believed to be a key process that influences the final performance of the devices. A significant effect on the photovoltage behavior can be observed experimentally depending on the extent of cleaning [4]. For this reason; TCO glass substrates have been thoroughly cleaned before film deposition. The glass cleaning protocol was, first cleaned with Acetone then with isopropanol finally with Ethanol. In all case the cleaning process was done in ultrasonic bath for about 20 minute in each solvent.

\subsubsection{ZnO Paste Formation}

$30 \mathrm{mg}$ of polyethylene glycol (dispersing agent) and $10 \mathrm{ml}$ of distilled water was mixed. $1.8 \mathrm{~g}$ of $\mathrm{ZnO}$ powder continuously grinded down by using procelain mortar to break down the aggregated particle. Then $2.5 \mathrm{ml}$ of the PEG solution was slowly added to the powder and completely mixed with each other by using the mortar. Finally the paste was ready for deposition.
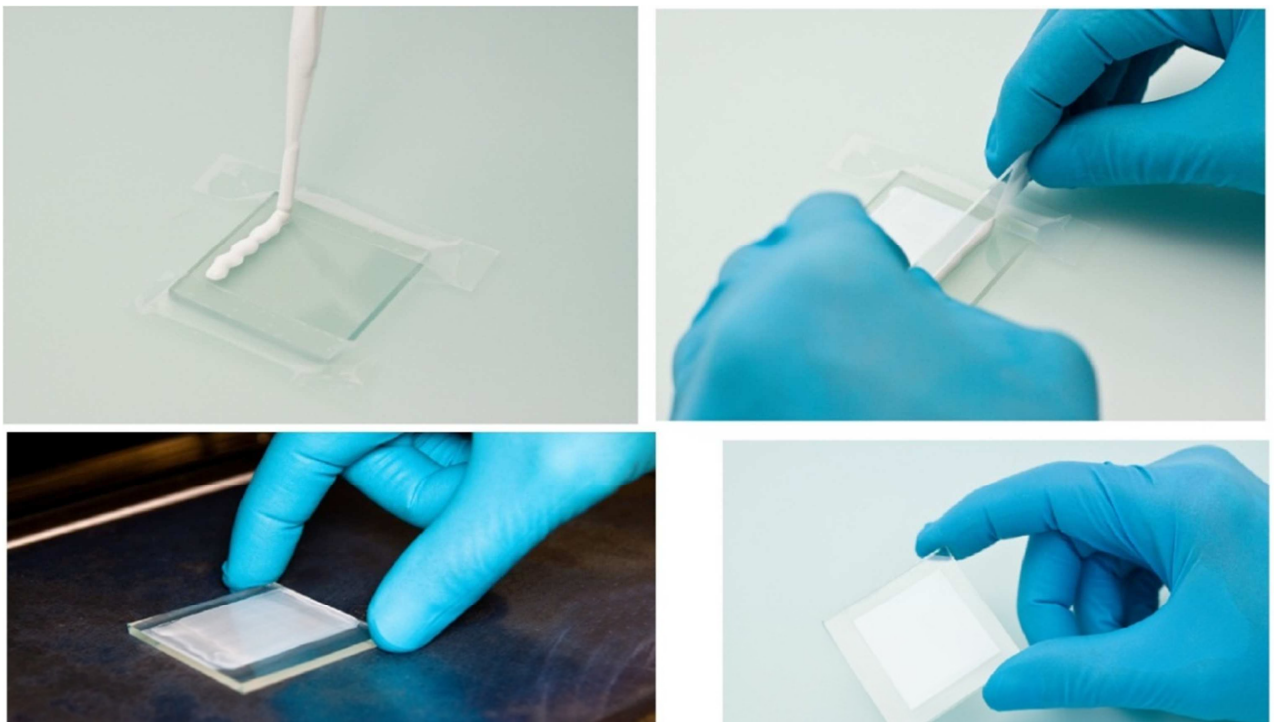

Fig. 5. Deposition of $\mathrm{ZnO}$ oxide paste. 


\subsubsection{Deposition of ZnO Films}

The simplest and most widely used method for depositing $\mathrm{ZnO}$ paste on a substrate is the so called doctor blade method. The technique is also known as slot coating in its mechanized version. It uses a hard squeegee, or doctor blade, to spread a portion of $\mathrm{ZnO}$ paste onto the glass (see Fig.5).

With the conductive side facing up, we apply four parallel strips of tape on the edges of the glass plate, covering about small portion of glass. After making the paste ready for deposition we apply the portion of paste near the top edge of the TCO glass between the two pieces of tape with the help of a glass rod, then, the paste spread across the plate with the support of the tape on all sides. The preparation of electrode was completed by firing the deposited layer. The organic solvent burns away, leaving the $\mathrm{ZnO}$ nanoparticles sintered together. This process ensures electrical contact between particles and good adhesion to the TCO glass substrate.

\subsubsection{Electrode Sensitization}

Natural dyes were used for electrode sensitization in the course of this thesis. Before immersion in the dye solution, films were warmed up to higher temperature $\left(80^{\circ} \mathrm{C}\right)$ to minimize the water vapor content inside the porous of the semiconductor electrode. The sensitization was always performed at room temperature. The best method of adsorbing a natural sensitizer to the oxide layer is by dipping the electrode in a solution of the dye already prepared. After sensitization, the films were rinsed in the same solvent (ethanol, water) as employed in the dye solution.

\subsubsection{Quasi-Solid State Electrolyte}

The polymer gel electrolyte was prepared according to the method developed by L. Fan et al as described below [5]. 0.9 $\mathrm{M}$ of 1-ethylene-3-methyl immidazolium iodide (EMIM-I) was added into acetonitrile (Aldrich) under stirring to form a homogeneous liquid electrolyte. In order to obtain a better conductivity, $0.5 \mathrm{M}$ of sodium iodide (BDH) was dissolved in the above homogeneous liquid electrolyte, and then $0.12 \mathrm{M}$ iodine and $35 \%(\mathrm{w} / \mathrm{w})$ of PVP (Aldrich) were added. Then, the resulting mixture was heated at $70-80^{\circ} \mathrm{C}$ under vigorous stirring to dissolve the PVP polymer, followed by cooling down to room temperature to form a gel electrolyte.

\subsubsection{Coating Counter Electrodes}

The poly (3, 4-ethylenedioxythiophene) (PEDOT) film for the counter electrode was formed by electrochemical polymerization of 3, 4-ethylenedioxy-thiophene (EDOT) (Aldrich), in a three electrode one-compartment electrochemical cell. The electro- chemical cell consisted of a pre cleaned ITO-coated glass working electrode, platinum foil counter electrode and quasi $\mathrm{Ag} / \mathrm{AgCl}$ reference electrode dipped in LiClO4 (Aldrich) acetonitrile (sigma-Aldrich) solution. The solution used for the polymerization contained $0.1 \mathrm{M}$ EDOT and $0.1 \mathrm{M} \mathrm{LiClO} 4$ in acetonitrile (SigmaAldrich). The monomer was used as received. The polymerization was carried out potentiostatically at $+1.8 \mathrm{~V}$. At this potential, the electrode surface becomes covered with blue-doped PEDOT film. The film was then rinsed with acetonitrile and dried in air.

\subsubsection{Assembly of DSSCs for Characterization}

Here the sensitized electrode was washed by the solvent of the dye then by ethanol and dried using hair dryer to dry the electrode, and then the non-covered part of the film by the paste was covered by a tape spacer in all side by leaving some place for electrical contact. By facing the active sides of the photoanode and the cathode, the two electrodes are pressed together after putting the quasi electrolyte on the photoanode. Then the devices are ready for characterization.

\section{Results and Discussion}

\subsection{ZnO Nanoparticles Size Determination}

Fig 6 is the plot of absorbance versus wavelength of the colloidal $\mathrm{ZnO}$ nanoparticles. From the absorption maxima the corresponding wavelength $\lambda=366 \mathrm{~nm}$ was obtained which is used for calculation of energy bandgap of the nanoparticle.

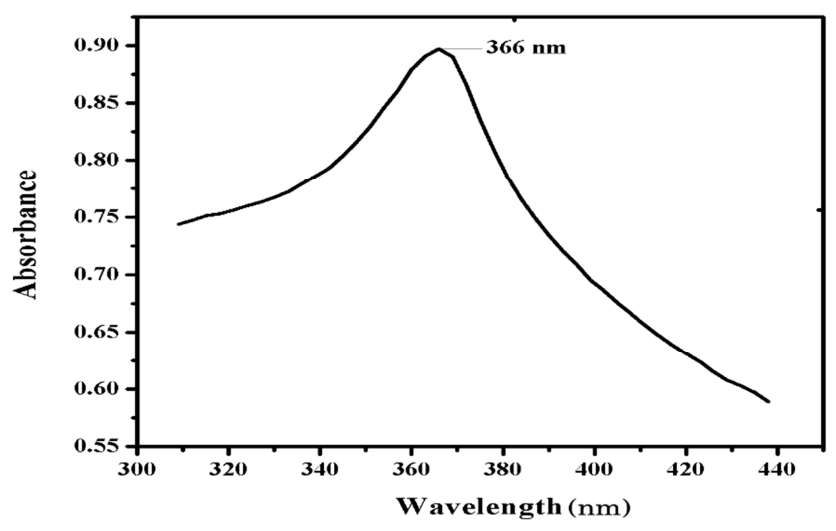

Fig. 6. Plot of absorbance versus wavelength for colloidal $\mathrm{ZnO}$ nanoparticle.

Using this wavelength the energy bandgap of the nanoparticle $\mathrm{E}_{\mathrm{g}}$ was calculated using Equation 1:

$$
E_{g}^{(\text {nano })}(R)=E_{g}^{(\text {bulk })}+\frac{h^{2}}{8 m_{0} R^{2}}\left(\frac{1}{m_{e}^{*}}+\frac{1}{m_{h}^{*}}\right)-\frac{1.8 e^{2}}{\varepsilon_{r} \varepsilon_{0} R}
$$

Where $\mathrm{m} 0, \mathrm{~m}_{\mathrm{e}}{ }^{*}$, and $\mathrm{m}_{\mathrm{h}}{ }^{*}$ are the rest mass of electron, effective masses of electron, and effective mass of hole respectively $[6,7,8]$. Rearranging Equation 5 and solving for $\mathrm{R}$ gives:

$$
R=\frac{\left(-\frac{1.8 e^{2}}{\varepsilon_{r} \varepsilon_{0}}\right) \pm \sqrt{\left(\frac{1.8 e^{2}}{\varepsilon_{r} \varepsilon_{0}}\right)^{2}\left(E_{g}^{(\text {nano })}-E_{g}^{(b u l k)}\right) \frac{h^{2}}{8 m_{0} R^{2}}\left(\frac{1}{m_{e}^{*}}+\frac{1}{m_{h}^{*}}\right)}}{E_{g}^{(\text {nano })}-E_{g}^{(\text {bulk })}}
$$


For $\mathrm{E}_{\mathrm{g}}{ }^{\text {(nano) }}$ of $3.39 \mathrm{eV}$, the radius of nanoparticle, $\mathrm{R}$ was obtained to be $5.7 \mathrm{~nm}$. Finally it is possible to say that the nanoparticle prepared by the method which was mentioned in the experimental part has an approximate average particle size of $11.4 \mathrm{~nm}$

\subsection{Optical Absorption Measurements}

The absorption spectrum of the prepared dye was measured by using the Genesys- 2 PC spectrometer. Here first, some amount of the final dye solution was put in the quartz cuvette, and the absorbance versus wavelength measurement was taken for each sample of ethanol and $\mathrm{H}_{2} \mathrm{O}$ extract. The results of absorbance measurement of each sample was shown in Fig. 7.

In water extract of Bougainvillea spectabilis [Fig. 7 (a)] two peaks were found: the first one around $485 \mathrm{~nm}$ which can be associated to the presence of indicaxanthin (which is a type of betaxanthin found in plant pigment), while the second one at $531 \mathrm{~nm}$ is attributable to the betacyanin pigment. The pigment extracted from Carissa Ovata using water extracted shows an absorption peak at $553 \mathrm{~nm}$ [Fig. 7 (b)]. In water extract, the spectra show an absorption peak in the region of $520-550 \mathrm{~nm}$ which is the peak of anthocyanin containing dyes.

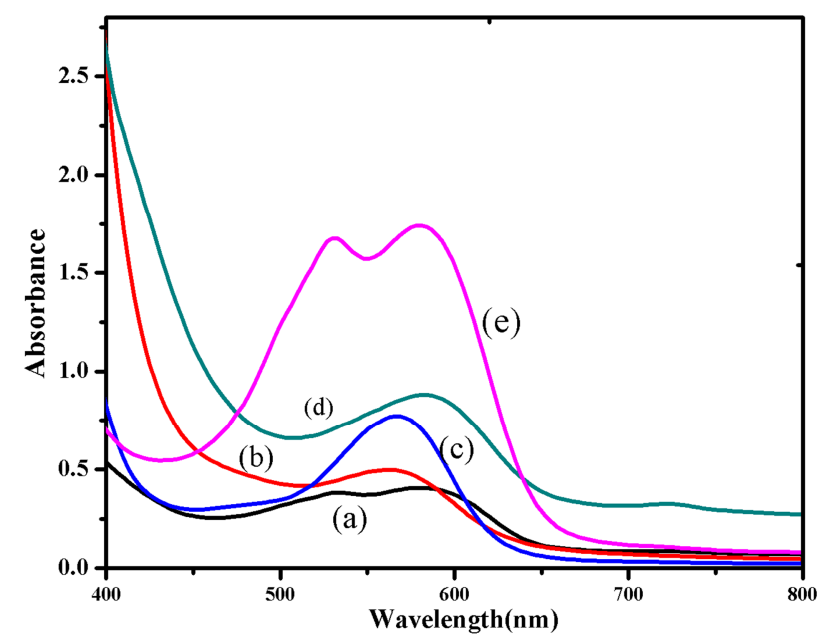

Fig. 7. Light Absorption spectra of dye solutions extracted with water of (a) Bougainvillea spectabilis, (b) Carissa Ovata, (c) Hibiscus sabdariffa, (d) Amarathus iresine herbisti, (e) Beta vulgaris.

This is because of the diverse pigmentation from orange to red, purple, and blue pigment which are found in anthocyanin containing pigment and shows an absorption in the visible region (approximately 490 - $550 \mathrm{~nm}$ ) [9].

Water extract of Hibiscus sabdariffa shows absorption peak at $519 \mathrm{~nm}$. The peak ascertains the presence of anthocyanin pigment [Fig. 7 (c)]. In water extract of Amarathus iresine herbisti [Fig. 7 (d)] $\left(\lambda_{\max }=532 \mathrm{~nm}\right)$ anthocyanin containing pigment were observed in the absorption spectra. Beta vulgaris showed an intense absorption peaks in the region $400-600 \mathrm{~nm}$ [Fig. 7 (e)]. Here also water extract shows strong absorption peak of betalians, which are at $470 \mathrm{~nm}$ and $533 \mathrm{~nm}$ due to the mixed contributions of the yellow-orange betaxanthins, and of the red-purple betacyanines at around $480 \mathrm{~nm}$ and $540 \mathrm{~nm}$ respectively [10].

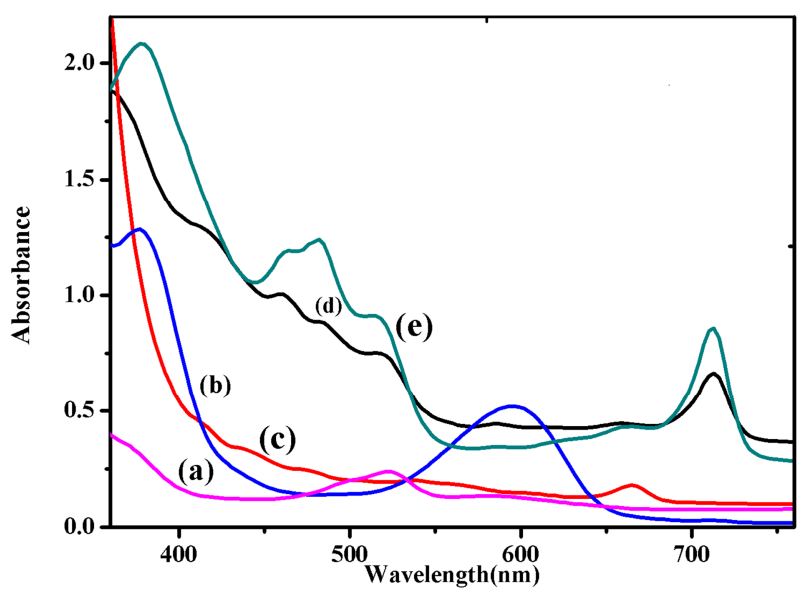

Fig. 8. Light Absorption spectra of dye solutions extracted with ethanol of (a) Beta vulgaris, (b) Hibiscus sabdariffa, (c) Carissa Ovata, (d) Bougainvillea spectabilis, (e) Amarathus iresine herbisti.

Ethanol extract of Bougainvillea spectabilis shows an absorption peak at $664 \mathrm{~nm}$ which has also an absorption peak below $500 \mathrm{~nm}$ [Fig. 8 (d)]. From these peak it is clearly shown that ethanol extract contain both chlorophyll a and $b$ which have an absorption peak in between $400-500 \mathrm{~nm}$ and $600-700 \mathrm{~nm}$ [11]. The pigment extracted from Carissa Ovata [Fig. 8 (c)] using ethanol shows an absorption peak at $664 \mathrm{~nm}$. In ethanol extract of Carissa ovata the extracted pigment was contain chlorophyll pigment which shows the characteristics absorption peak of chlorophyll.

Both water and ethanol extract of Hibiscus sabdariffa [Figs. 7(c) and 8(b))] shows absorption peaks at $549 \mathrm{~nm}$ and $519 \mathrm{~nm}$ respectively. The peaks are associated with presence of anthocyanin pigment. Beta vulgaris [Fig. 8 (a)] showed an intense absorption peaks in the region $400-600 \mathrm{~nm}$. Here also both water and ethanol extract shows strong absorption peak of betalians, at $470 \mathrm{~nm}$ and $533 \mathrm{~nm}$ because of the mixed contributions of the yellow-orange betaxanthins and the red-purple betacyanines (480, and $540 \mathrm{~nm}$ respectively) [5] Ethanol extract of Amarathus iresine herbisti $\left(\lambda_{\max }=433\right.$, $464,664 \mathrm{~nm}$ ) indicates the presence of chlorophyll which absorb most of the blue and red light [Fig. 8 (e)].

\subsection{Current Density Versus Voltage Characteristics of $\mathrm{ZnO}$ Based DSSCS}

The J-V characteristic of all sensitizers were measured and plotted for analysis and made comparison as shown below. Figure 9 (b) is ethanol extract of Beta vulgaris, the current density decreases as compared to the water extract [Fig. 10 (d)], but the reverse is true for the open circuit voltage. This is due to the low injection rate of electron into the semiconductor conduction band which decreases the short circuit current. 
Water extract of Hibiscus sabdariffa [Fig. 10 (e)] has showed better current than the corresponding ethanol extract [Fig. 9 (c)] with some increment in short circuit current density.

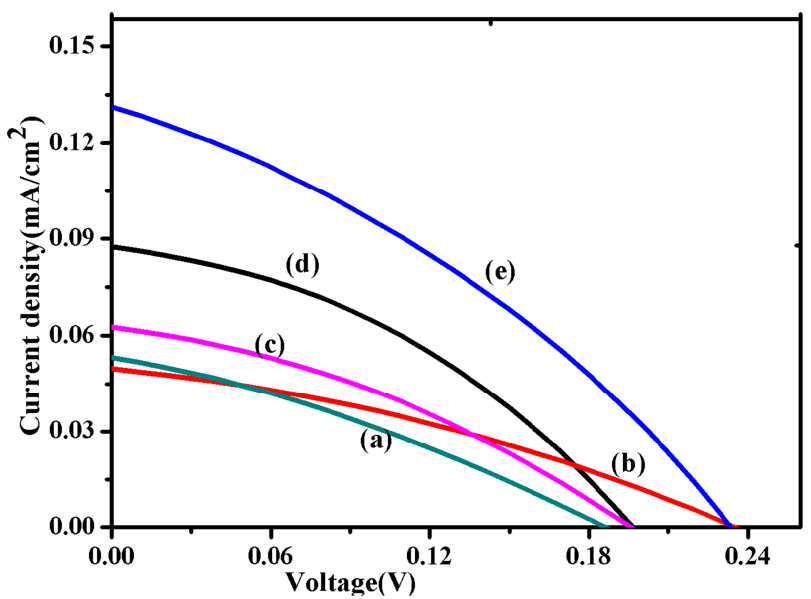

Fig. 9. J-V of ZnO based DSSCs extracted with ethanol, (a) Carissa ovate, (b) Beta vulgaris, (c) Hibiscus sabdariffa, (d) Bougainvillea, (e) Amarathus iresine herbisti.

In Fig. 10 (c), (d) and Fig. 10 (b), (e) both water and ethanol extract almost they have the same open circuit voltage but the current density relatively higher for ethanol than the water extract which means that there is only a difference in electron injection efficiency. Most of the natural dye which have a good and a broader absorption in the visible spectrum are expected to show a good rectification of the J-V curve that is responsible for good current density and power conversion efficiency. In these studies ethanol extract of Carissa ovata, Bougainvillea spectabilis, and Amarathus iresine herbisti shows a better rectification which results relatively good photoelectrochemical performance for ethanol extract than the water extract. In ethanol and water extract of Hibiscus sabdariffa, Bougainvillea spectabilis, and Carissa ovata, during socking, it was clearly an observed that, the film starts to dissolve.
This is because of protons derived from sensitizers make the dye solution relatively acidic which leads to the dissolution of the $\mathrm{ZnO}$ colloid.

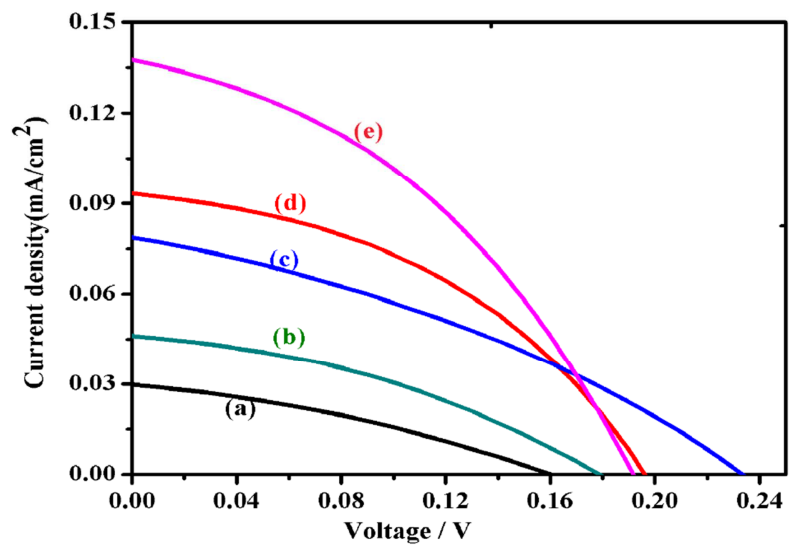

Fig. 10. J-V of ZnO based DSSCs extracted with water, (a) Bougamvillia spectabilis, (b) Carissa ovata, (c) Amarathus iresine herbisti, (d) Beta vulgaris, (e) Hibiscus sabdariffa.

The low local $\mathrm{pH}$ at the surface of $\mathrm{ZnO}$ during dye sensitization leads to the dissolution of $\mathrm{Zn}^{2+}$ ions from the $\mathrm{ZnO}$ surface [Fig. 11 (2)]. These $\mathrm{Zn}^{2+}$ ions form complexes with the dye [Fig. 11 (3)], which accumulate in the pores of the semiconductor film. It is assumed that only dye molecules directly attached to the $\mathrm{ZnO}$ surface can inject efficiently electrons and contribute to the photocurrent [12]. Therefore, $\mathrm{Zn}^{2+} /$ dye complexes, in spite of absorbing light, do not inject electrons. So that the low current as well as low power conversion efficiency may arises due to the above reasons. The instability of $\mathrm{ZnO}$ in acidic dyes results due to its amphoteric nature. In general, in a solution, the surface of the oxide is predominantly positively charged at a $\mathrm{pH}$ below the point of zero charge and negatively charged above this value, while the point of zero charge of metal oxides is defined as the $\mathrm{pH}$ at which the concentrations of protonated and deprotonated surface groups are equal.

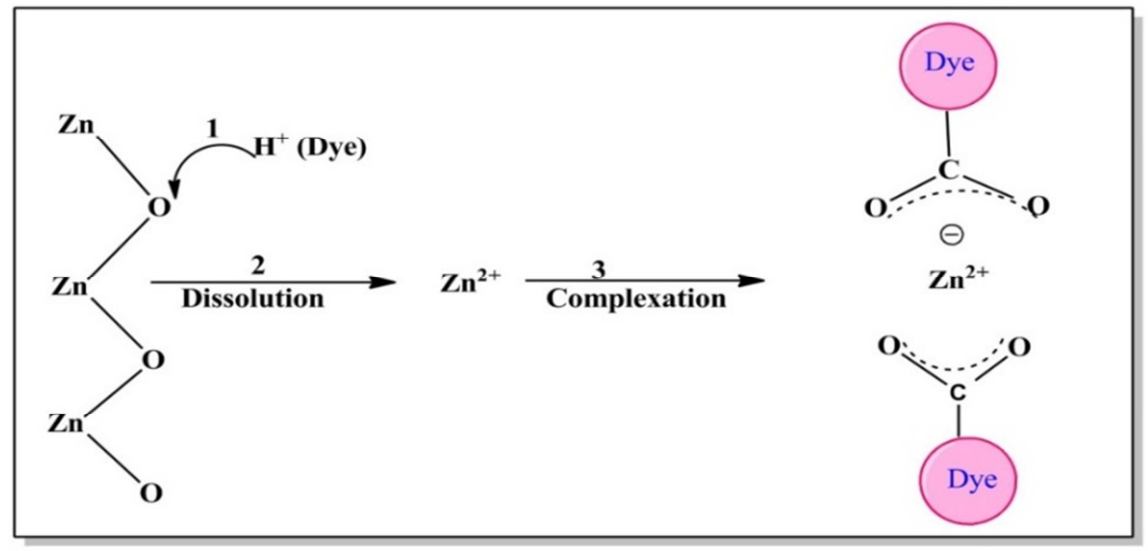

Fig. 11. $\mathrm{Zn}^{2+} /$ dye complexes formation.

For example the $\mathrm{ZnO}$ sensitization process with $\mathrm{Ru}-$ complex dye, the $(\mathrm{pH}=5)$ is much lower than the point of zero charge of $\mathrm{ZnO}(\approx 9)$. That means that the $\mathrm{ZnO}$ surface is positively charged. Thus, the protons adsorbed on the $\mathrm{ZnO}$ 
surface will dissolve the $\mathrm{ZnO}$. Table 1 Summarized the performance of the DSSCs in terms of short-circuit photocurrent $\left(\mathrm{J}_{\mathrm{sc}}\right)$, open-circuit voltage $\left(\mathrm{V}_{\mathrm{oc}}\right)$, fill factor $(\mathrm{FF})$, and energy conversion efficiency $(\eta)$ compared to those of other extracts.

The efficiency of cell sensitized by the Amarathus iresine herbistii extracted with ethanol was the best among the others. This is due to broader absorption range of the sensitizers, higher interaction between $\mathrm{ZnO}$ nanocrystaline film and the pigment extracted from Amarathus iresine herbistii which leads to a better charge transfer. The current density and open circuit voltage it has higher value than the others which are $0.29 \mathrm{mAcm}-2$ and $0.29 \mathrm{~V}$ respectively. The fill factor also shows best value of $48.5 \%$ for ethanol extract of Amarathus iresine herbisti.

Table 1. Photovoltaic performance of ZnO based DSSCs with different sensitizers.

\begin{tabular}{llllll}
\hline Sensitizers & Solvent & $\begin{array}{l}\mathbf{J}_{\text {sc }}(\mathbf{m A c} \\
\left.\mathbf{m}^{-2}\right)\end{array}$ & Voc & $\begin{array}{l}\mathbf{F F} \\
\mathbf{( \% )}\end{array}$ & $\boldsymbol{\eta} \mathbf{( \% )}$ \\
\hline Carissa Ovata & Water & 0.041 & 0.18 & 36.8 & 0.0027 \\
& Ethanol & 0.053 & 0.19 & 30.7 & 0.0031 \\
Beta vulgaris & Water & 0.094 & 0.20 & 41.3 & 0.0077 \\
& Ethanol & 0.050 & 0.24 & 33.0 & 0.0039 \\
Bougainvillea & Water & 0.030 & 0.17 & 31.5 & 0.0016 \\
spectabilis & Ethanol & 0.088 & 0.20 & 37.4 & 0.0066 \\
Hibiscus & Water & 0.137 & 0.20 & 38.1 & 0.0104 \\
sabdariffa & Ethanol & 0.063 & 0.20 & 34.3 & 0.0043 \\
Amarathus & Water & 0.079 & 0.24 & 32.6 & 0.0062 \\
iresine & Ethanol & 0.290 & 0.29 & 48.5 & 0.0390 \\
\hline
\end{tabular}

As reported in literature, [13] that the extracting solvent can affect the DSSCs performance. The efficiency of the DSSCs was found to increase immensely when ethanol was used for extracting pigments [13]. In this study, similar finding was also obtained. This might be due to the fact that our extracted pigments are more soluble in ethanol as a result; the aggregation of dye molecules decreases as expected. Better dispersion of dye molecules on the oxide surface could exactly improve the efficiency of the system.

\subsection{Photocurrent Action Spectra of ZnO Based DSSCs}

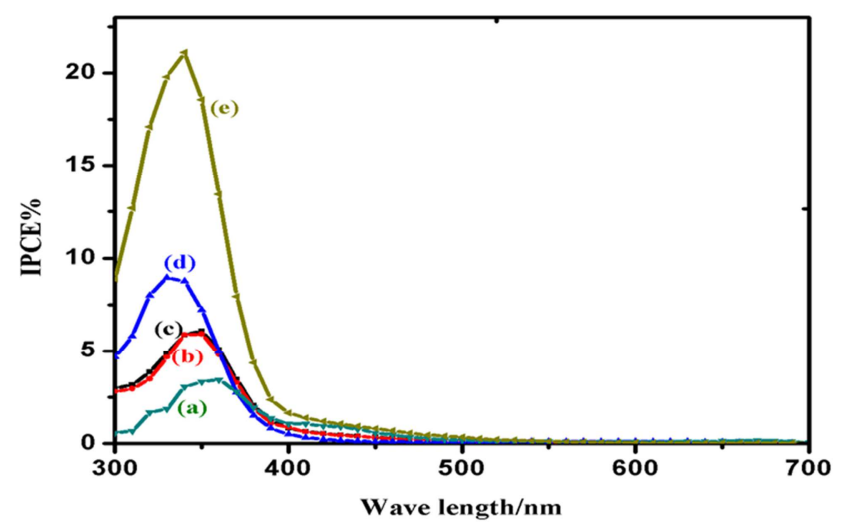

Fig. 12. IPCE of ZnO based DSSC sensitizers extracted with ethanol, (a) Amarathus iresine herbisti, (b) Carissa ovata, (c) Bougainvillea spectabilis, (d) Hibiscus sabdariffa, (e) Beta vulgaris.
The Photo action spectra [Figs. 12 and 13] provided further insights on the photoelectrochemical behavior of natural dyes. All the following figures shows the incident photon to current conversion efficiency (IPCE) spectra of $\mathrm{ZnO}$ electrodes sensitized with all of our extracted natural dyes as a function of wavelength. Some of the IPCE spectra of the organic dyes adsorbed on the $\mathrm{ZnO}$ electrodes are broader than the absorption curves of the dyes in solution.

Ethanol extract of Bougainvillea spectabilis [Fig. 12(c)], Carissa ovate [Fig. 12(b)], Hibiscus sabdariffa [Fig. 12(d)], Beta vulgaris [Fig. 12(e)], and Amarathus iresine herbisti [Fig. 12(a)], shows broad IPCE spectrum up to 610,720, 430, 460, 550, $710 \mathrm{~nm}$, respectively [Fig. 12]. Water extract of Bougainvillea spectabilis, Carissa ovata, Hibiscus sabdariffa, Jacaranda mimosifolia, Beta vulgaris, and Amarathus iresine herbisti from 300 up to 550, 730, 700, 460, 550, $650 \mathrm{~nm}$, respectively [Fig. 13], which showed some sensitization effect, but there spectrum is dominated by the spectrum of the $\mathrm{ZnO}$ nanoparticles. The IPCE of $\mathrm{ZnO}$ sensitized by carisa ovate and Hibiscus sabdariffa shows a red shift on the absorption onset for water extract than ethanol extract.

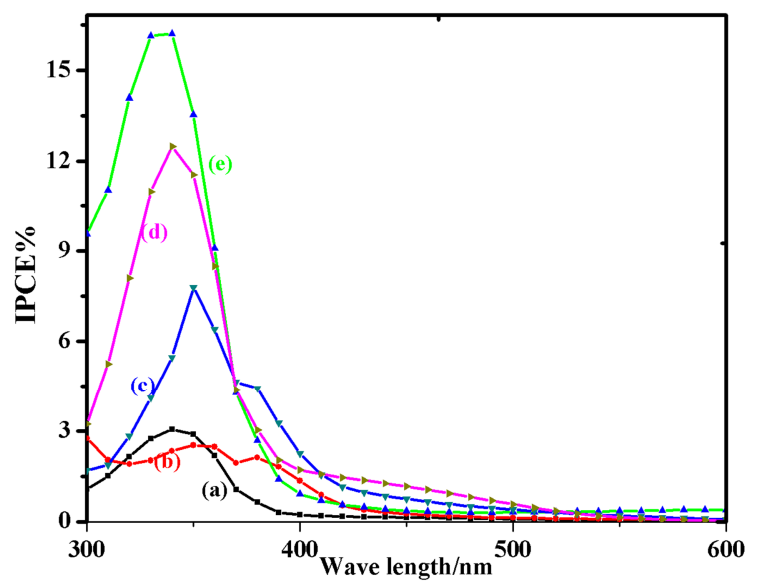

Fig. 13. J-V of ZnO based DSSCs sensitizers extracted with water, (a) Bougamvillia spectabilis, (b) Carissa ovate, (c) Amarathus iresine herbistii, (d) Beta vulgaris, (e) Hibiscus sabdariffa.

Low IPCE results in either inefficient light harvesting efficiency (LHE) by the dye, or inefficient charge injection into $\mathrm{ZnO}$, or inefficient collection of injected electrons. A low LHE can be due to a low dye absorption coefficient over the solar spectrum, a low dye concentration, a thin $\mathrm{ZnO}$ film to support large concentration of adsorbed dye which absorbs a significant fraction of the incident light, insufficient light scattering within the film, absorption of light by $\mathrm{ZnO}$ or the redox electrolyte, and dye degradation [14].

Low $\eta_{\text {inj }}$ can be due to dye desorption, dye aggregation or the excited state levels of the dye lying below the conduction band edge of $\mathrm{ZnO}$, the presence of the surrounding electrolyte, the wavelength of the exciting photon. Low $\eta_{\mathrm{cc}}$ is due to competition between fast recombination of photoinjected electrons with the redox electrolyte or oxidized dye and electron collection. The formation of $\mathrm{Zn}^{2+} /$ dye complex can agglomerate which comes from dissolution of the 
nanostructured film form a thick covering layer instead of a monolayer, and is therefore inactive for electron injection which also limit the incident photon to current conversion efficiency. In IPCE of $\mathrm{H}_{2} \mathrm{O}$ extract of Carissa ovata, both $\mathrm{H}_{2} \mathrm{O}$, and ethanol extract of Amarathus iresine shows additional spectral peaks which are a quite strong evidence of aggregate formation [15]. The presence of aggregated dyes or non-injecting dyes at the surface affects all parameters. In all DSSCs device studied a small value of the incident to photon conversion efficiency, short circuit current, and fill factor were obtained that leads to small solar to electricity conversion efficiency [16].

In view of the instability of $\mathrm{ZnO}$ in acidic dyes, the development of new types of photosensitizers for use in $\mathrm{ZnO}$ DSSCs is a subject that has already been widely investigated. These photosensitizers are expected to be chemically bonded to the $\mathrm{ZnO}$ semiconductor, be charge transferable with high injection efficiency, and be effective for light absorption in a broad wavelength range. New types of dyes should be developed with the aim of fulfilling these criteria. For our study some of the chlorophyll extract shows relatively good efficiency for ethanol extract than water extract.

In water extract of natural dye, increased socking time of the film will leads to the dissolution of $\mathrm{ZnO}$ nanoparticle on the ITO, this is because of the extraction solvent (water) possesses an acidic nature, protons derived from dissolution of the dye makes the dye solution relatively acidic and this may be one of the reason for decrease in the short-circuit photocurrent. Also upon long socking time, formation of aggregate are formed which can be center of charge recombination and decrease the photovoltaic effects.

Generally, natural dyes suffer from low $\mathrm{V}_{\mathrm{oc}}$, and $\mathrm{J}_{\mathrm{sc}}$ which leads lower power conversion efficiency than an equivalent commercial N719 sensitized cell. This is because of most of natural dyes didn't completely attached to the $\mathrm{ZnO}$, and $\mathrm{TiO}_{2}$ nanoparticles, even upon washing by solvent to avoid aggregation from the socked film, the sensitizers leave the surface of the film, this is due to, more of the natural dye attached with film of the nanoparticles by physical attaching or by a weak bonding force.

\section{Conclusion}

In this work, $\mathrm{ZnO}$ nanoparticle was successfully synthesized which is one of the major semiconductors for DSSCs, using polyethylene glycol as dispersing agent. The average particle size of these semiconductor nanoparticles was determined using an approximation model called the effective mass model. From optical absorption spectra the maximum absorption $\lambda_{\max }$ was determined which was used for finding the energy band gap of the nanoparticles. From the effective mass approximation which relates the radius of nanoparticle with its energy bandgap the size of $\mathrm{ZnO}$ nanoparticle was determined to be $1.14 \mathrm{~nm}$.

DSSCs device are fabricated using $\mathrm{ZnO}$ nanoparticles for the six sensitizers and their photovoltaic performance were determined. For ethanol extract of Bougainvillea spectabilis,
Carissa ovata, Amarathus iresine herbistii, Beta vulgaris, and Hibiscus sabdariffa, efficiency of $0.0066 \%, 0.0031 \%$, $0.039 \%, 0.0039 \%$, and $0.0043 \%$ respectively were obtained. The efficiency of water extract of Bougainvillea spectabilis, Carissa ovata, Amarathus iresine herbistii, Beta vulgaris, and Hibiscus sabdariffa were found $0.0016 \%, 0.003 \%$, $0.0062 \%, 0.0077 \%$, and $0.0104 \%$ respectively.

In general, $\mathrm{ZnO}$ nanoparticles based DSSCs shows low photoelectrochemical performance as compared to commercial $\mathrm{TiO}_{2}$ based DSSCs. Some of the limiting factor for this was insufficient attachment of natural dyes with the nanoparticles, formation of aggregation between the nanoparticles up on film formation, low injection rate, low regeneration of electron, and formation of $\mathrm{Zn}^{2+}$ /dye complex. Therefore, modification of $\mathrm{ZnO}$ aggregates with a very effective shell material on $\mathrm{ZnO}$, preventing the generation of $\mathrm{Zn}^{2+} /$ dye agglomerates will be a good method for improving the stability of $\mathrm{ZnO}$ nanoparticles.

\section{References}

[1] B. O'Regan and M. Gratzel, "A low-cost, high-efficiency solar cell based on dye-sensitized colloidal $\mathrm{TiO}_{2}$ films", Nature, vol. 353, pp. 737-740, 1991.

[2] Y. Yen, W. Chen, C. Hsu, H. Chou, J. Lin, M. Yeh, "Arylamine-Based Dyes for p-Type Dye-Sensitized Solar Cells”. Org. Lett., vol. 13, pp. 4930, 2011.

[3] W. Campbell, K. Jolley, P. Wagner, K. Wagner, P. Walsh, K. Gordon, Schmidt-Mende, M. Nazeeruddin, Q.Wang, M. Grätzel, "Highly Efficient Porphyrin Sensitizers for DyeSensitized Solar Cells" J. Phys. Chem. C, vol. 111, pp. 11760, 2007.

[4] P. J. Cameron, L.M. Peter, and S. Hore. "How important is the back reaction of electrons via the substrate in dye-sensitized nanocrystalline solar cells", J. Phys. Chem., vol. 109, no.2, pp. 930-4936, 2005.

[5] L. Fan, S. Kang, J. Wu, S. Hao, Z. Lan, J. Lin, "Quasi-Solid State Dye-sensitized Solar Cells Based on Polyvinylpyrrolidone With Ionic Liquid", J. Energy Sources A. vol. 32, pp. 1559. 2010.

[6] J. Singh, "Effective mass of charge carriers in amorphous semiconductors and its applications, Journal of NonCrystalline Solids", vol. 299, pp. 444-448, 2002.

[7] J. Zhang, P. Zhou, J. Liu, J. Yu, "New understanding of the difference of photocatalytic activity among anatase, rutile and brookite $\mathrm{TiO}_{2}$ ", Phys. Chem. Chem. Phys., vol. 16, pp. 2038220386, 2014.

[8] N. H. Quang, N. T. Truc, Y. M. Niquet, "Computational Materials Science", vol. 44, pp. 21-25, 2008.

[9] K. Wongcharee, V. Meeyoo and S. Chavadej, "Dye-sensitized solar cell using natural dyes extracted from rosella and blue pea flowers", Sol. Energy Mater. Sol. Cells, Vol. 91, pp. 566$571,2007$.

[10] H. Horiuchi et al., "Electron injection efficiency from excited $\mathrm{N} 3$ into nanocrystalline $\mathrm{ZnO}$ films: Effect of (N3-Zn2+) aggregate formation" J. Phys. Chem. B, vol.107, pp. 2570257, 2003. 
[11] H. Chang and Y.-J. Lo, "Pomegranate leaves and mulberry fruit as natural sensitizers for dye-sensitized solar cells," Solar Energy vol. 84 no.10, pp. 1833-1837, 2010.

[12] S. Hao, J. Wu, Y. Huang, J. Lin, "Natural dyes as photosensitizers for dye-sensitized solar cell," Sol. Energy vol. 80, no.9, pp. 209-214 2006.

[13] Z.-S. Wang and F. Liu, "Structure-property relationships of organic dyes with D- $\pi$-A structure in dye-sensitized solar cells," Front. Chem. China, vol. 5, pp. 150-161, 2010.
[14] H. Zhou, L. Wu, Y. Gao, T. Ma, "Dye-sensitized solar cells using 20 natural dyes as sensitizers," J. Photochem. Photobiol. A: Chemistry, vol. 219, pp. 188-194, 2011.

[15] H. Hubert B. Michael, M. Peter, G. Thilo, "Natural pigments in dye-sensitized solar cells", Applied Energy vol. 115, pp. 216-225, 2014

[16] Z. Qifeng, S. Christopher, Z. Xiaoyuan, "ZnO Nanostructures for Dye-Sensitized Solar Cells" Adv. Mater. Vol. 21 no. 41, pp. 4087-4108, 2009. 